\title{
Blood cultures on internal medicine: utilization profile and clinical implications
}

\author{
Hemoculturas em medicina interna: perfil de utilização e implicações clínicas
}

Gustavo Nobre de Jesus ${ }^{1,2}$, João Trindade Nave ${ }^{1,2}$, Luís Santos Pinheiro ${ }^{1,2}$, João Meneses Santos ${ }^{1,2}$, Margarida Lucas ${ }^{1,2}$, Rui M. M. Victorino ${ }^{1,2}$

\begin{abstract}
Introduction: recent literature suggests that excessive use of blood cultures could prolong length of stay and hospital costs. Moreover, low positive rates have been reported and positivity predictive scores have recently been proposed. Methods: we conducted an observational prospective study in an Internal Medicine department of a university reference hospital analysing data from all patients to whom BC was requested. Results: blood cultures were performed in $39.9 \%$ of 414 admissions. Patients with blood cultures had higher length of stay and underwent more laboratory and imaging diagnostic tests. Global positivity rate was of $7.5 \%$. Patients fulfilling sepsis criteria had a higher positivity rate $(21.7 \%)$ and there were no positive blood cultures in patients without sepsis, namely in cases of isolated creactive protein elevation, leucocytosis or fever. In addition, blood cultures results were not a determinant of antibiotic adjust or de-escalation. Conclusions: our data suggest that the use of BC should be done essentially in patients with sepsis criteria, reducing its unnecessary use, although more studies are required to validate such practice.
\end{abstract}

Keywords: Blood Culture. Sepsis. Internal Medicine. Microbiology.

\section{RESUMO}

Introdução: o uso excessivo de hemoculturas tem sido associado a aumento do tempo de internamento e de custos hospitalares. Adicionalmente, a literatura médica reporta taxas de positividade abaixo do esperado, levando à criação de índices de predição de positividade. Métodos: estudo prospectivo observacional conduzido numa enfermaria de Medicina Interna de um hospital terciário, com recolha de dados de todos os doentes a quem foram realizadas hemoculturas. Resultados: em 414 admissões, foram colhidas hemoculturas em $39.9 \%$. Os doentes a quem foram colhidas hemoculturas tiveram maior tempo de internamento e mais exames laboratoriais e imagiológicos pedidos. 7,5\% das hemoculturas foram positivas. Nos doentes com critérios de sepsis a taxa de positividade das hemoculturas foi $21,7 \%$ e não houve nenhuma hemocultura positiva em doente sem critérios de sépsis, nomeadamente em doentes com elevação isolada de proteína c-reactiva, leucocitose ou febre. O resultado da hemocultura não foi um determinante de de-escalação antibiótica. Conclusões: este estudo sugere que as hemoculturas devem ser colhidas essencialmente em doentes com sepsis, podendo esta prática diminuir o seu sobreuso.

Palavras-chave: Hemocultura. Sepse. Medicina Interna. Microbiologia.

1. Clinica Universitária de Medicina 2, Hospital Santa Maria, Lisboa, Portugal

2. Faculdade de Medicina, Lisboa, Portugal

Conflict of interest

The author(s) declare(s) that there is no conflict of interest regarding the publication of this paper. 


\section{Introduction}

Blood cultures (BC) remain the gold standard for the diagnosis of bloodstream infections. Positivity rates in unselected settings vary between 9 and $20 \%{ }^{1}$ and in patients fulfilling sepsis criteria can be as high as $66 \% .^{2}$ Widespread use of BC has been thoroughly debated. ${ }^{1,3}$. Recent papers suggest that overuse of BC may be responsible for prolonging hospital length of stay (LoS) and higher hospital costs, without relevant impact on mortality. ${ }^{4}$ Direct utility of $\mathrm{BC}$ when measured by therapeutic changes based on its results is limited. According to a study by Corbo et al in 355 admissions for community acquired pneumonia, only in $5 \%$ of patients the antibiotic was changed based on BC results. ${ }^{5}$

Simple measures can be taken in order to optimize and rationalize the use of $\mathrm{BC}$, namely adoption of more strict criteria and emphasis on the importance of microbiological analysis of other biological products like urine, sputum or pleural liquid. ${ }^{6}$ Such practices can reduce $B C$ use as much as $18 \%$ with important cost-reductions. ${ }^{6,7}$ Efforts have been made for the development of BC positivity prediction tools, either based on integrated scores or focused on independent variables, but none has achieved convincing results. Severity of infection still seems to be the strongest predictor of $B C$ positivity 8,9 and more in depth information on $\mathrm{BC}$ overuse and related clinical outcomes is crucial.

The aim of our study was to characterize in the setting of an Internal Medicine Department the use and burden of $\mathrm{BC}$, its indications and utility and its relationship with clinical outcome variables.

\section{Material and Methods}

An observational study was conducted with information gathered from the clinical files of all discharged patients during 3 months in an Internal Medicine (IM) department of a university reference hospital. The main variables included: age; gender; presumptive diagnosis of infection; LoS; death; number and result of $\mathrm{BC}$; reason to order $\mathrm{BC}$; clinical setting (Emergency department [ED] vs ward) and number of imagiologic and laboratory exams ordered.

Data were collected using a structured form designed specifically for this study. Blood cultures were ordered according to medical criteria of the attending physicians and there were no prestudy orientations. Blood cultures were collected using the standard microbial detection systems available in the hospital (BacT/ALERT ${ }^{\circledR}$, Biomérieux Inc. Durham, N.C., EUA and BD BACTEC ${ }^{\mathrm{TM}}$, Becton, Dickinson and Company, Shannon, Ireland) and no data was obtained concerning the puncture-site or details of the procedure.

The unit for analysis was the series of $\mathrm{BC}$ done at the same time in a given patient (BC episode) and not the individual BC. The following agents were considered skin contaminants: Coagulase-negative staphylococcus; Propionibacterium spp; Peptostreptococcus spp; Corynebacterium spp; Micrococcus spp. Blood culture episodes were classified as: i) positive (at least two BC were positive for specimens other than contaminants); ii) dubious (only one of the $B C$ had an isolated specimen or if the isolate was one of the contaminants) and iii) negative (no specimens identified).

The analysis was divided in subgroups: patients with/without infection, according to the diagnosis used by clinicians on medical files; patients with/without BC and patients with/without sepsis (Surviving Sepsis Campaign criteria applied by the investigators. ${ }^{10}$

For statistical analysis SPSS version 21 (IBM Inc.) was used. Discrete variables were described with frequency tables and continuous variables with means and standard deviations. Chi-square test was used for bivariate analysis of dichotomous variables and t-student test for continuous variables. Multivariate scenarios were analysed with binary logistic regression. Results were considered significant for $\mathrm{p}$ values below 0.05 .

\section{Results}

A total of 414 admissions were analysed, with a predominance of female gender $(54.8 \%)$, mean age of 73.0 years, mean LoS of 7,4 days (11.7 in patients with BC) and an overall mortality rate of $9,4 \%$. Blood cultures were performed in 165 admissions $(39.9 \%)$ and characterization of patients is detailed in table 1 . Mortality rate was consistently more elevated in the patients in whom BC were performed (17.0\%). Subgroup analysis of patients with and without infection criteria revealed higher mortality in the first group ( $13,5 \%$ vs $4,7 \%)$. Higher mortality in patients to whom BC were collected 
persists even in the group of patients without infection criteria, although less pronounced.

Out of 464 individual BC, 201 BC episodes were considered. The mean number of $\mathrm{BC}$ per episode was 2.8 (range from 1 to 5 ) as described in table 2 . The group with BC had higher mean laboratory and imagiologic exams ordered per patient (figure 1).

The global positivity rate of individual $B C$ was $7.5 \%$, but this value was significantly higher for $B C$ ordered in the ED (15.4\%). All positive BC were done in patients with sepsis criteria (table 3 ).
Blood culture usefulness was assessed using as surrogate the change of antibiotic strategy as consequence of BC result. From all the 201 BC episodes, antibiotic therapy was used in 172 at any point of the episode. In 63 of those the antibiotic was changed during hospital stay $(31.3 \%)$, but only $21(12.2 \%)$ were based on the BC result, even in cases classified as dubious. Moreover, only in 10 cases there was antibiotic de-escalation based on positive or dubious $\mathrm{BC}$ result, representing less than $5 \%$ of all the BC episodes.

Table 1: Comparison between patients with or without blood cultures.

\begin{tabular}{|c|c|c|c|c|c|c|}
\hline & All patients & $\begin{array}{c}\text { Patients } \\
\text { without } \mathrm{BC}\end{array}$ & $\begin{array}{l}\text { Patients } \\
\text { With BC }\end{array}$ & $\begin{array}{l}\text { p-value } \\
\text { (bivariate } \\
\text { analysis) }\end{array}$ & $\begin{array}{c}\text { p-value } \\
\text { (multivariate } \\
\text { analysis) }\end{array}$ & $\begin{array}{l}\text { Odds } \\
\text { Ratio }\end{array}$ \\
\hline Admissions & $414(100 \%)$ & $249(60.1 \%)$ & $165(39.9 \%)$ & & & \\
\hline Gender (female) & $54.8 \%$ & $57.8 \%$ & $50.3 \%$ & 0.93 & 0.384 & $\mathrm{~N} / \mathrm{S}$ \\
\hline Mean age (years) & 73.0 & 71.9 & 74.6 & 0.003 & 0.578 & $\mathrm{~N} / \mathrm{S}$ \\
\hline LoS (mean days) & 7.4 & 4.6 & 11.7 & $<0.0001$ & $<0.0001$ & 1.126 \\
\hline Mortality & 33 & $11(4.4 \%)$ & $28(17 \%)$ & $<0.0001$ & $<0.0001$ & 1.762 \\
\hline $\begin{array}{l}\text { Mortality in patients with } \\
\text { presumptive infection }\end{array}$ & $39(13.5 \%)$ & $4(4.9 \%)$ & $26(18.3 \%)$ & $<0.0001$ & & \\
\hline $\begin{array}{l}\text { Mortality in patients } \\
\text { without infection }\end{array}$ & $9(4.7 \%)$ & $7(4.2 \%)$ & $2(8.7 \%)$ & $<0.0001$ & & \\
\hline
\end{tabular}

(Bivariate analysis with chi-square or t-student. Multivariate analysis [logistic regression] included gender, mean age, LoS, mortality and presumptive infection for the dependent variable "performing blood culture" [n: total number of admissions; LoS: length of stay])

Table 2: Number of blood cultures drawn by episode of blood culture.

\begin{tabular}{lcc}
\hline & Number of episodes & \% of episodes \\
\hline BC drawn & 8 & 4.0 \\
3 BC drawn & 138 & 68.7 \\
4 BC drawn & 45 & 22.3 \\
5 BC drawn & 7 & 3.5 \\
\hline Total of BC drawn & 3 & 1.5 \\
\hline
\end{tabular}




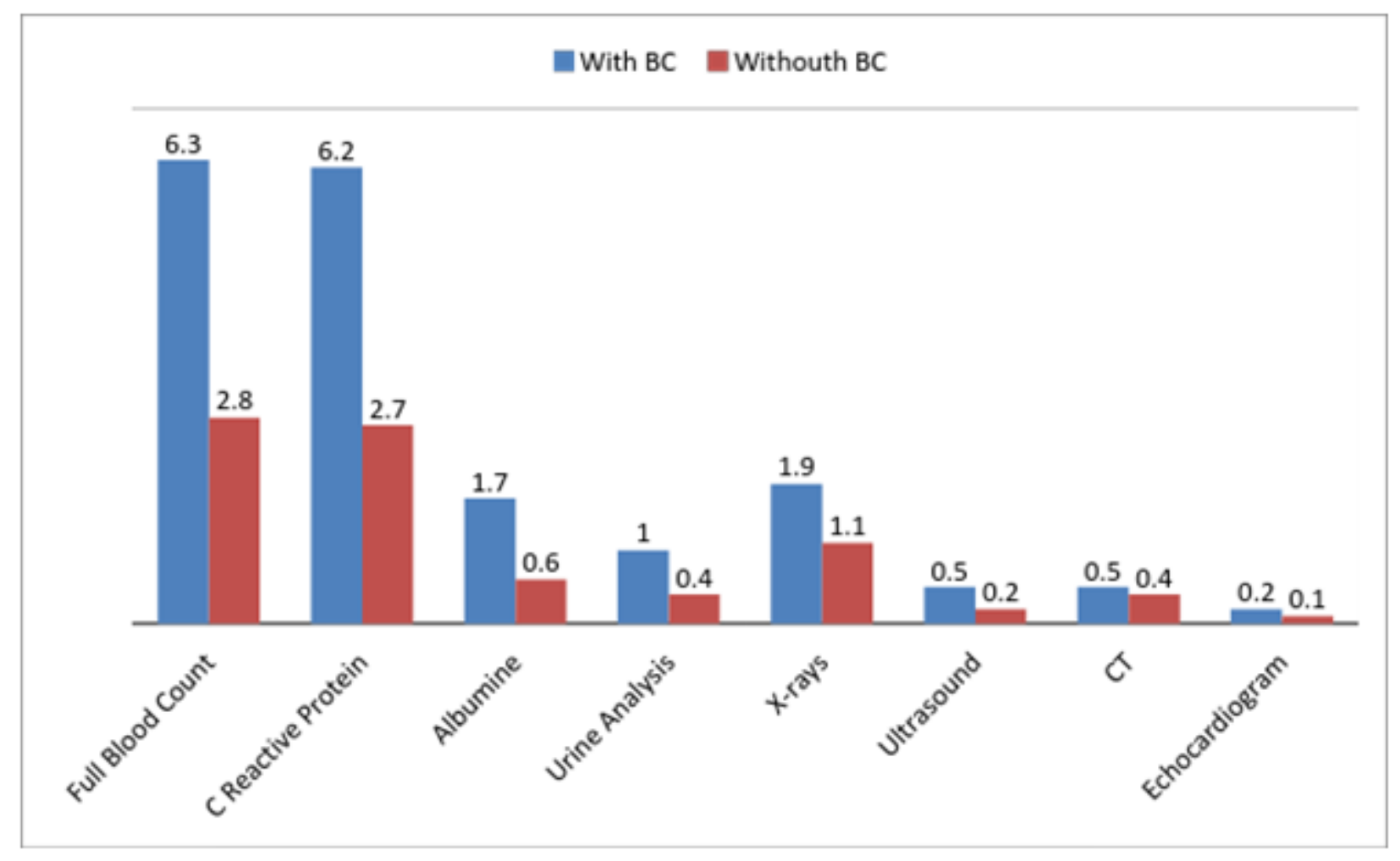

Figure 1: Laboratorial and imagiological exams per patient (means), according to BC ordering. (BC: Blood Culture; CT: Computorized tomography)

Table 3: BC positivity according to setting and reason to order BC.

\begin{tabular}{|c|c|c|c|c|}
\hline & BC Positive & BC Dubious & BC Negative & Total \\
\hline \multicolumn{5}{|l|}{ Setting } \\
\hline ED & $4(15.4 \%)$ & $2(7.7 \%)$ & $20(76.9 \%)$ & 26 \\
\hline Ward & $11(6.2 \%)$ & $14(7.9 \%)$ & $152(85.9 \%)$ & 177 \\
\hline \multicolumn{5}{|c|}{ Reason to order BC } \\
\hline Sepsis & $15(8.6 \%)$ & $13(7.4 \%)$ & $147(84.0 \%)$ & 175 \\
\hline Leucocytosis * & $0(0 \%)$ & $0(0 \%)$ & $2(100.0 \%)$ & 2 \\
\hline CPR elevation * & $0(0 \%)$ & $1(6.3 \%)$ & $15(93.8 \%)$ & 16 \\
\hline Fever * & $0(0 \%)$ & $0(0 \%)$ & $7(100.0 \%)$ & 7 \\
\hline Control & $0(0 \%)$ & $0(0 \%)$ & $3(100.0 \%)$ & 3 \\
\hline Total n (\%) & $15(7.5 \%)$ & $15(7.5 \%)$ & $171(85.1 \%)$ & 201 \\
\hline
\end{tabular}

(BC: Blood culture; ED: Emergency department; CPR: C-reactive protein; * - patients without sepsis criteria) 


\section{Discussion and Conclusion}

These results on the use of $B C$ in an Internal Medicine ward reveal an excessive utilization and moreover patients to whom BC are ordered have higher LoS, more exams ordered and higher mortality. Such results can not be directly attributed BC ordering itself, but rather it is likely that clinicians request of $\mathrm{BC}$ is related to the perception of unclear diagnosis and to the severity of the underlying clinical condition. This is particularly relevant in internal medicine wards, where multiple comorbidities, severe infectious or non-infectious diseases and complications during hospital stay are frequent. $4,11,12$

Our positivity rate is slightly lower than in other series, which can be attributed to the several BC performed in patients with low-severity infection, namely patients who do not meet sepsis criteria. ${ }^{13}$ It has been proposed that severity of infection may be the best predictor of positivity of BC, but the way to assess this remains controversial. ${ }^{14}$ Scores have attempted to predict positivity, since it has been suggested that more precise criteria is required. ${ }^{15}$ Shapiro et al, ${ }^{13}$ for instance, gathered information concerning patients' history, co-morbidities, physical examination and laboratory results that were incorporated in a scale that determined with high sensitivity which patients would benefit from BC. However, our work suggests that the presence of sepsis criteria might be the most relevant single marker to reduce the number of $\mathrm{BC}$, although this requires further validation. Thus, improvement in sepsis recognition may be more useful and simple than the application of complex positivity prediction scores.

The fact that in our series BC results were not a determinant of antibiotic changes or de-escalation indicates reduced usefulness of $B C$ in this setting. Blood cultures are known to have higher positivity rates in patients with more severe infections and further studies may clarify in which situations BC do have a real impact on clinical outcomes. ${ }^{16}$ Site of infection may also play a role in deciding the true value of performing a $\mathrm{BC} .{ }^{17}$ More than deciding in which patients to order a $B C$, our study helps to select patients in whom BC could be avoided. As previously described, ${ }^{18,19}$ many $B C$ are ordered to patients with simple elevation of C-reactive protein, leucocytosis or fever, and in this setting positivity rates can be extremely low, as documented in our study, where there was no single positive $\mathrm{BC}$ in this context.

The clinical setting has been proposed as a relevant factor in excessive $\mathrm{BC}$ ordering, ${ }^{1,6}$ and in fact it has been suggested that ED and night-shift physicians ordered more tests in the assumption that this was the expected practice by the attending physician. However, our study indicates that the $\mathrm{BC}$ collected on ED had a higher positivity rate, suggesting a good degree of appropriateness in this setting. In any case, the emphasis should be put on the importance of clinical recognition of sepsis, irrespective of clinical setting.

In conclusion, this study suggests that in patients admitted in an Internal Medicine wards it is reasonable to perform BC essentially on patients who fulfil current sepsis criteria. Further studies may clarify in which situations BC offer true benefit to the patient, in order to define more precisely its use.

\section{References}

1. Ehrenstein BP1, Ehrenstein V, Henke C, Linde HJ, Salzberger B, Schölmerich J, Glück T. Risk factors for negative blood cultures in adult medical inpatients - a retrospective analysis. BMC Infect Dis. 2008; 28;8:148..

2. Towns ML, Jarvis WR, Hsuesh PR. Guidelines on blood cultures. J Microbiol Immunol Infect. 2010; 43:347-9.

3. Tabriz MS, Riederer K, Baran J Jr, Khatib R. Repeating blood cultures during hospital stay: practice pattern at a teaching hospital and a proposal for guidelines. Clin Microbiol Infect. 2004;10:624-7.

4. Inglis TJ1, Hodge M, Ketharanathan S. A hospital-wide study of the impact of introducing a personal data assistant-augmented blood culture round. J Med Microbiol. 2008;57(Pt 1):43-9.

5. Corbo J, Friedman B, Bijur P, Gallagher EJ. Limited usefulness of initial blood cultures in community acquired pneumonia. Emerg Med J. 2004;21:446-8.

6. Kelly AM; Clinical impact of blood cultures taken in the emergency department. J Accid Emerg Med. 1998.15:2546.

7. Makam AN, Auerbach AD, Steinman MA. Blood culture use in the emergency department in patients hospitalized with respiratory symptoms due to a nonpneumonia illness. J Hosp Med. 2014; 9: 521-4.

8. Previsdomini M, Gini M, Cerutti B, Dolina M, Perren A. Predictors of positive blood cultures in critically ill patients: a retrospective evaluation. Croat Med J. 2012; 53:30-9.

9. Makam AN, Auerbach AD, Steinman MA. Blood culture use in the emergency department in patients hospitalized for community-acquired pneumonia. JAMA Intern Med. 2014 May; 174(5):803-6 
10. Dellinger RP, Levy MM, Rhodes A, Annane D, Gerlach $H_{\text {, }}$ Opal SM, et al. Surviving Sepsis Campaign Guidelines Committee including The Pediatric Subgroup. Surviving Sepsis Campaign: international guidelines for management of severe sepsis and septic shock, 2012. Intensive Care Med. 2013;39:165-228

11. Chotirmall SH, Callaly E, Lyons J, O'Connell B, Kelleher M, Byrne D, et al. Blood cultures in emergency medical admissions: a key patient cohort. Eur J Emerg Med. 2014; 23: 38-43.

12. Dellinger RP, Levy MM, Carlet JM, Bion J, Parker MM, Jaeschke $R$, et al. Surviving Sepsis Campaign: international guidelines for management of severe sepsis and septic shock: 2008. Crit Care Med. 2008;36:296-327.

13. Shapiro NI, Wolfe RE, Wright SB, Moore R, Bates DW. Who needs a blood culture? A prospectively derived and validated prediction rule. J Emerg Med. 2008;35:255-64.

14. Wildi K, Tschudin-Sutter S, Dell-Kuster S, Frei R, Bucher HC, Nüesch R. Factors associated with positive blood cultures in outpatients with suspected bacteremia. Eur J Clin Microbiol Infect Dis. 2011;30:1615-9.
15. Roque P1, Oliver B, Anderson L, Mulrow M, Drachman D, Stapczynski S, LoVecchio F. Inpatient utilization of blood cultures drawn in an urban ED. Am J Emerg Med. 2012;30:110-4.

16. Ishikawa $G 1$, Nishimura $N$, Kitamura $A$, Yamano $Y$, Tomishima $Y$, Jinta T, Chohnabayashi N. Impact of blood cultures on the changes of treatment in hospitalized patients with community-acquired pneumonia. Open Respir Med J. 2013 Jul 12;7:60-6

17. Campbell SG1, Marrie TJ, Anstey R, Dickinson G, AckroydStolarz S. The contribution of blood cultures to the clinical management of adult patients admitted to the hospital with community-acquired pneumonia: a prospective observational study. Chest. 2003 Apr;123(4):1142-50.

18. Ehrenstein BP, Jarry $T$, Linde $H J$, Schölmerich J, Glück T. Low rate of clinical consequences derived from results of blood cultures obtained in an internal medicine emergency department. Infection 2005;33;314-319

19. Coburn B, Morris AM, Tomlinson G, Detsky AS. Does this adult patient with suspected bacteremia require blood cultures? JAMA. 2012;308:502-11. 